\title{
Effect of Pressing Parameters on the Quality of Joint Formation of Heat Exchanger Fins with the Base Plate
}

\author{
Marek Kowalik ${ }^{1}$, Tomasz Trzepiecinski², and Hirpa G. Lemu ${ }^{1 . *}$ \\ ${ }^{1}$ Kazimierz Pulaski University of Technology and Humanities in Radom, Institute of Mechanical \\ Engineering, ul. Krasickiego 54, 26-600 Radom, Poland \\ ${ }^{2}$ Rzeszow University of Technology, Department of Materials Forming and Processing, al. Powst. \\ Warszawy 12, 35-959 Rzeszów, Poland \\ ${ }^{3}$ University of Stavanger, Department of Mechanical and Structural Engineering and Materials \\ Science, N-4036 Stavanger, Norway
}

\begin{abstract}
In this paper, the results of experimental and numerical studies on joining the thin fins to the thick base plate of a heat exchanger are presented. The elements of the heat exchanger were joined by using developed method of press forming. The joining technology consists in clamping the sheet metal into the channel of the base plate using a punch with specific geometry. The effect of different configurations of the punch geometry (shape, radius and distance between fin and punch) and the indentation depth on the depth of the interface between the fin and base plate is analysed. Furthermore, the effect of different combinations of finbase plate materials has been numerically studied. The plate material was the AA2219 -T851 aluminium alloy, while the fins were made of the AA5251 aluminium alloy. The elastic-plastic numerical computations of the joining process have been carried out using the finite element-based MSC.Marc program. It was found that the area of the contact of the fin with the base plate can be optimised by choosing the right parameters of the tool geometry and technological parameters. Experimental research has shown that increasing the punch indentation causes the material to flow in the transverse direction to the punch and the indirect extrusion in the region between the punches.
\end{abstract}

\section{Introduction}

Many joining technologies are used to create permanent or temporary joints in the assembly of constructional elements and subasemblies. Joining of thin-walled structures is mainly realized by welding, riveting or bolted joints [1-2]. The disadvantage of welding technology is the great influence on the properties of the joined material as a result of heat affected zone. Welding technologies cannot always be used due to the fact that they provide large amounts of heat to the connection area, which causes deformation of the structure joined [34]. In the case of making connections of non-ferrous metal sheets, the welding methods are

* Corresponding author: Hirpa.g.lemu@uis.no 
too expensive while also causing numerous technological difficulties. The riveted and screwed joints of the sheets without usage of sealants in general do not assure the joint leak-tightness. Another method is joining by using metal forming technology which creates permanent joints and allows to joint different kinds of constructional materials [5]. This method assures the high thermal and electrical conductivity between metal-to-metal joined sheets, leak-tightness and high mechanical capacity of the joint.

The issue of ensuring proper tightness between the metal-to-metal surfaces is particularly important when connecting thin fins to the base plate of the radiator (Fig. 1) to ensure a large contact surface between the materials being joined. The purpose of the fins is to increase the heat exchange surface. Radiators are made of materials with high thermal conductivity, for example aluminium and its alloys [6]. Thanks to the good conductivity, the heat from the base plate is distributed from a small area of contact to the surface of the entire radiator. Appropriate conduction is therefore of paramount importance for the even distribution of heat, so that all points of the radiator surface have the same temperature. Heat exchange between radiator fins and the environment takes place through conduction and radiation. Thermal conduction issues are the subject of significant research, both from scientific point of view and engineering applications. Simulation of temperature fields and analysis of heat transfer in engineering facilities, constructions, flow systems, and elements of machines is an indispensable part of their design and technical optimization of their construction.

Problems of transient and steady-state heat transfer in complex geometrically multielement spatial and flat areas are the subject of numerous studies both in analytical solutions [7], numerical computations [8,9], and experimental studies [10, 11].

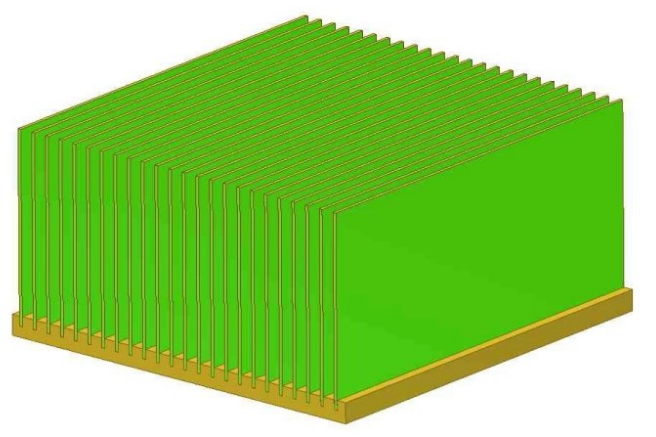

Fig. 1. Model of industrial heat exchanger

In this paper, the results of experimental and numerical studies on joining the thin fins to the thick base plate of heat exchanger are presented. The elements of the heat exchanger were joined by using developed method of press forming. The joining technology consists in clamping the sheet metal into channel of base plate using punch with specific geometry. The effect of different configurations of the punch geometry (shape, radius and span between) and the indentation depth on the depth of the interface between the fin and base plate is analysed.

\section{Experimental methodology}

The heat exchanger fins were joined to the base plate by indenting the punch that is pressed symmetrically following the geometry of the fins. The geometry of the base plate and fins is presented in Fig 2. The plate with a thickness of $15 \mathrm{~mm}$ is made of the AA2219 -T851 aluminium alloy, while the fins with a thickness of $1.5 \mathrm{~mm}$ were made of the AA5251 
aluminium alloy. The mechanical properties of the materials, including the strain hardening coefficient $K$ and strain hardening exponent $n$ in Hollomon equation $\sigma=K \cdot \varepsilon^{n}(\sigma-$ stress, $\varepsilon-$ plastic strain) that were determined in uniaxial tensile test are listed in the Table 1.

In experiments, a punch with a radius of $R=1 \mathrm{~mm}$ was employed. A series of experimental tests for different geometrical configurations of the joining parameters have been carried out. The applied punch indentations $z$ were between 0.1 and $0.4 \mathrm{~mm}$. The distance between the punch and the fin $l$ varied between 1.2 and $1.6 \mathrm{~mm}$. The proposed method of metal joining allows formation of dovetail like joints. The goal of the research was to receive the highest depth of the interface zone $h$ of the fin in the base plate. The fins were inserted in the channels milled in the base plate with dimensions of $150 \times 300 \times 15$ and then joined to the base plate.

Table 1. The basic mechanical properties of the base plate and fin material

\begin{tabular}{|c|c|c|c|}
\hline Material & $\begin{array}{c}\text { Yield stress } \boldsymbol{R}_{\mathbf{p 0 . 2}}, \\
\text { MPa }\end{array}$ & $\begin{array}{c}\text { Strength coefficient } \\
\boldsymbol{K}, \text { MPa }\end{array}$ & $\begin{array}{c}\text { Strain hardening } \\
\text { exponent } \boldsymbol{n}\end{array}$ \\
\hline AA5251 & 112 & 245 & 0.27 \\
\hline AA2219-T851 & 166 & 369 & 0.15 \\
\hline
\end{tabular}

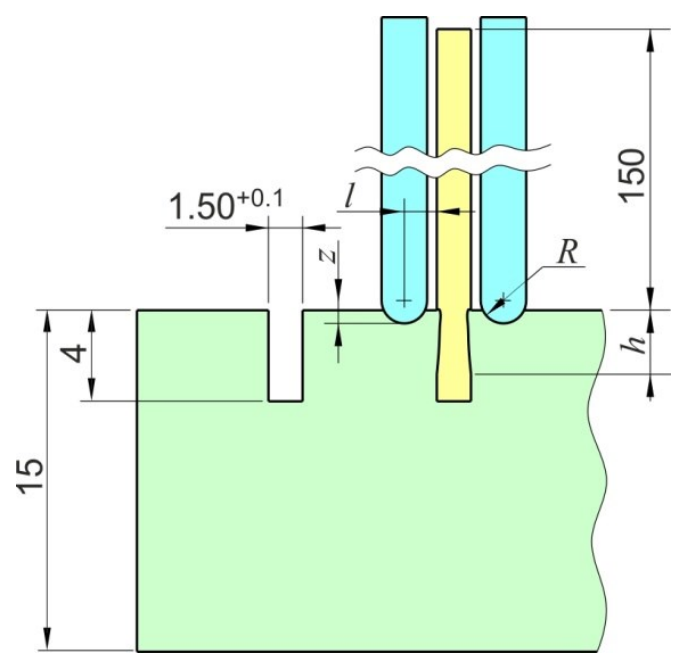

Fig. 2. Dimensions of the fins and plate.

\section{Numerical modelling}

The elastic-plastic numerical computations of the joining process have been carried out using finite element-based MSC.Marc program. Due to geometry of the forming process, the $2 \mathrm{D}$ plane strain model is considered. Geometry of the model corresponded to real forming process. The punch is considered as rigid, so only its external surface is considered. Numerical analyses were conducted for the maximum value of the groove in the base plate, which is equal to $1.6 \mathrm{~mm}$ according to the dimensional deviation (Fig. 2). To discretize both base plate and fin material, the four-node, isoparametric, arbitrary quadrilateral element was used assuming plane strain conditions. The stiffness of this element is formed using four-point Gaussian integration. This finite element (FE) is preferred over higher-order elements when used in a contact analysis [12]. In the area of expected high stains, the FE mesh was densified (Figure 3) with the average element size of $0.1 \mathrm{~mm} \times 0.1 \mathrm{~mm}$. 


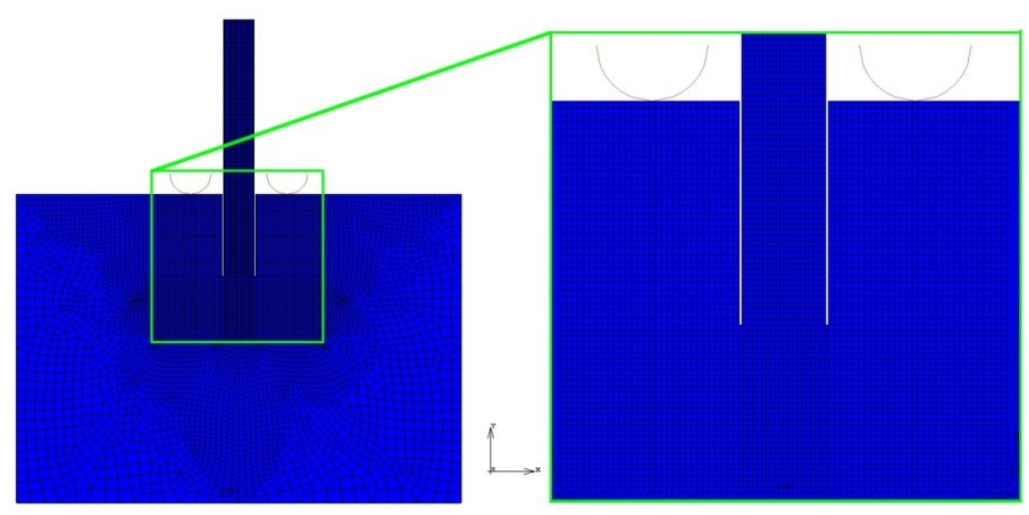

Fig. 3. FE mesh of the analysed problem

The model of the base plate was discretized into 8013 elements, while the fin is discretized into 3000 elements. The elastic-plastic behaviour of material including strain hardening phenomenon (Table 1) is considered. The density of both models is set to 2780 $\mathrm{kg} / \mathrm{m}^{3}$. The values of elastic properties of materials, i.e. Young's modulus and the Poisson's ratio were set equal to $73000 \mathrm{MPa}$ and 0.33 , respectively. In the case of high pressures, which existed in metal forming, the friction plays important role in the flow of deformed materials $[13,14]$. Friction between the plate and the tool was described by Coulomb's law with friction coefficient $\mu=0.15$ [5].

\section{Results}

For all the analysed distances between the punch and the fin $l$, the identical tendency of increasing depth of the interface zone $h$ with the increase of indentation depth $z$ (Fig. 4) was observed. The increase in the indentation depth $z$ led to increasing depth of the interface zone. However, the greater the indentation depth, the slower the increase in the depth of interface zone. In the case of the forming parameters $l=1.6 \mathrm{~mm}$ and $z=0.1 \mathrm{~mm}$, joining of the elements was not possible. Fig. 5 presents distribution of equivalent plastic strain for the indentation depth of $z=0.3 \mathrm{~mm}$ and different values of distances between the punch and the fin $l$.

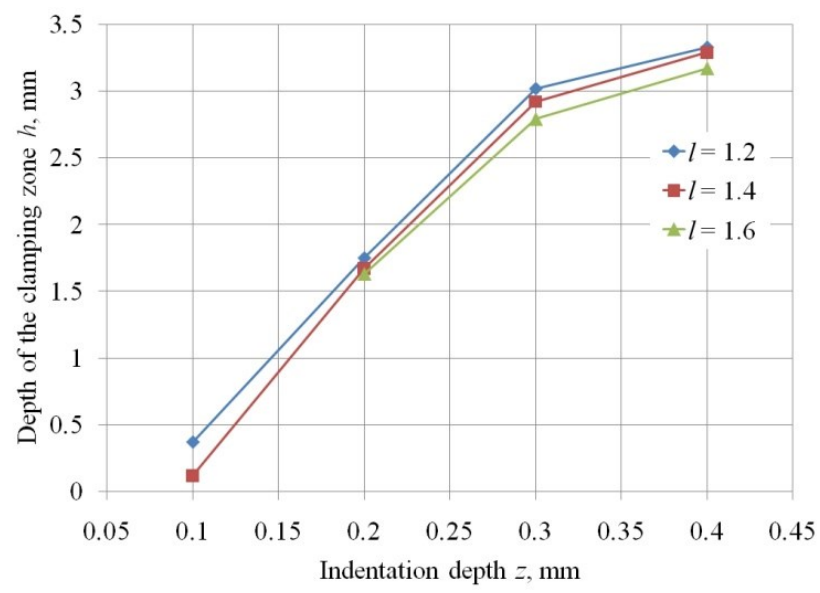

Fig. 4. Effect of indentation depth on the value of the depth of interface zone. 
The increase in the distance between the punch and the fin $l$ led to an identical form of material deformation (Fig. 5). The differences in the resulted depth of the interface zone in the range of the analysed distances between the punch and the fin $l$ do not exceed $0.25 \mathrm{~mm}$. So, the distance $l$ is not important factor in formation of the joint. In contrast the punch indentation value significantly influences the formation of the dovetail (Fig. 6).

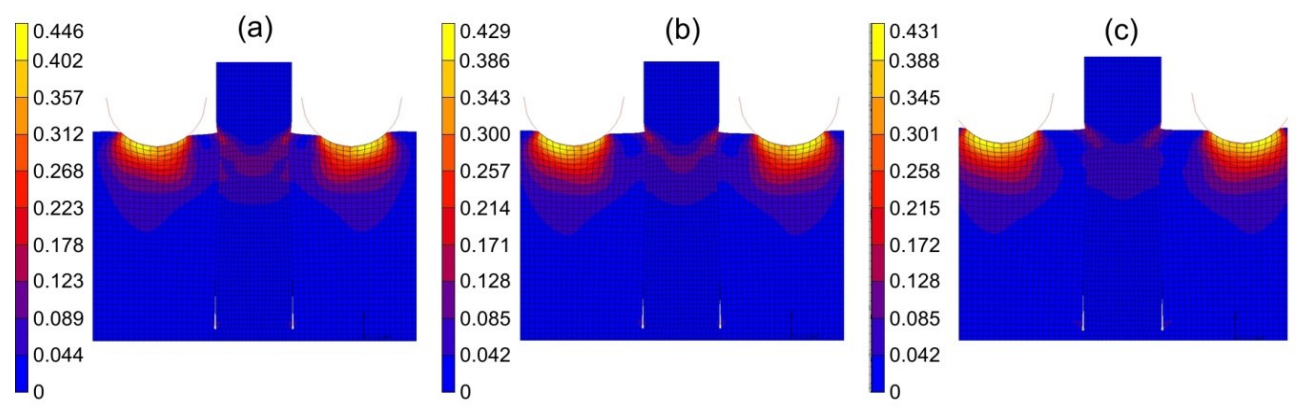

Fig. 5. Distribution of equivalent plastic strain for the punch indentation depth $z=0.3 \mathrm{~mm}$ and distances between the punch and the fin $l$ equals to (a) $1.2 \mathrm{~mm}$, (b) $1.4 \mathrm{~mm}$ and (c) $1.6 \mathrm{~mm}$

The lower the distance between the punch and the fin $l$ and the higher the punch indentation $z$, the higher plastic strains are observed in the upper part of the joint. So, the dovetail width goes to the lower values. It can be speculated that the lower width of the dovetail led to an increase in the pull out force of the fin from the base plate. Indentation of the punch gives rise to a local flow of the material. A large $l$-value can be limited by the fin spacing on the base plate.

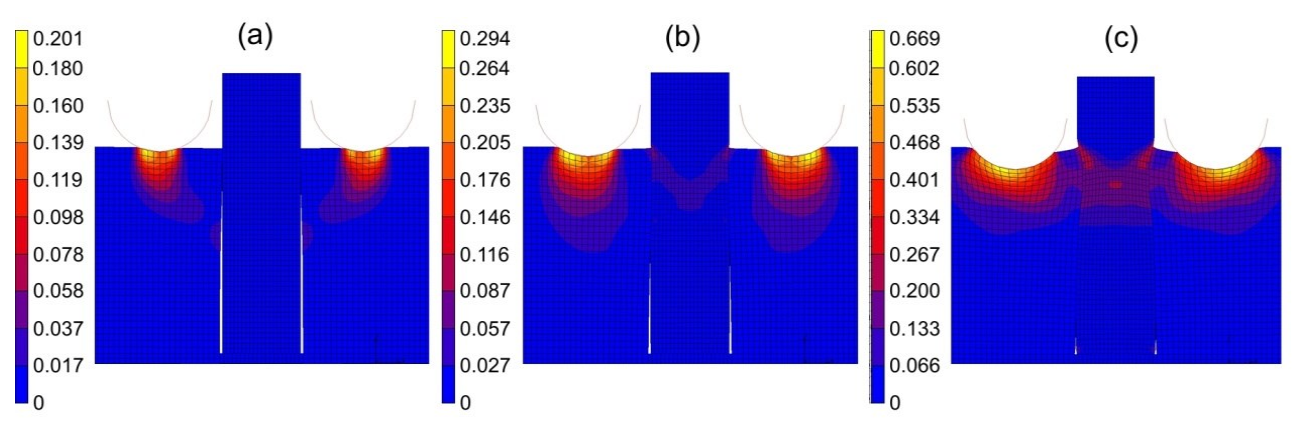

Fig. 6. Distribution of equivalent plastic strain for the distance between the punch and the fin $l=1.2$ $\mathrm{mm}$ and punch indentations of (a) $0.1 \mathrm{~mm}$, (b) $0.2 \mathrm{~mm}$ and (c) $0.4 \mathrm{~mm}$

\section{Conclusions}

The numerical computations of the developed method of joining the fins with the base plate of heat exchanger have yielded satisfactory results. By appropriate selection of technological parameters of the joining process, i.e. the distance between the punch and the fin $l$ and punch indentation depth, it is possible to form the suitable depth of the interface zone, which is the main parameter that influences the heat transfer between base plates and fins. It is found that the distance $l$ is not an important factor influencing the formation of the joint. On the other hand, the punch indentation values significantly influencing the formation of the dovetail dimensions are significantly dependent on the value of the punch indentation. 
As a continuation of this work, the focus of future research will be to check the possibility of forming a dovetail joint using other punches with varied shape and dimensions. Furthermore, the optimal selection of configurations of the materials of the heat exchanger elements can improve the filling of the base plate groove by fin material. Although the method presented is developed for joining the fins to the base plate of a heat exchanger, where the strength of the joint is not important criterion of joint quality, in the future the pull-out tests will be carried out.

\section{References}

1. Z. Chang, Z. Wang, L. Xie, Y. Kang, M. Xu, Z. Wang, Int. J. Adv. Manuf. Technol. 97, 2529 (2018)

2. C. Chen, S. Zhao, X. Han, X. Zhao, T. Ishida, Materials 10, E887 (2017)

3. S. Caruso, E. Sgambitterra, S. Rinaldi, A. Gallone, L. Viscido, L. Filice, D. Umbrello AIP Conf. Proc. 1769, 100004 (2016)

4. L. Han, M. Thornton, D. Boomer, M. Shergold, J. Mater. Process. Technol. 210, 1076 (2010)

5. M. Kowalik, T. Trzepieciński, Arch. Civ. Mech. Eng. 12, 292 (2012)

6. R.L. Webb, N.H. Kim, J. Enhanc. Heat Transf. 14, 1 (2007)

7. P. Cheng, S.S. Dua, Int. J. Heat Mass Tran. 18170 (1975)

8. Y. Qian, Z. Han, J.H. Zhan, X. Liu, G. Xu, Int. J. Heat Mass Tran. 127, 573 (2018)

9. L. Garelli, G.R. Rordiguez, J.J. Dorella, M.A. Storti, Int. J. Therm. Sci. 137, 64 (2019)

10. G.A. Oliveira, E.M.S. Contreras, E.P.B. Filho, Appl. Therm. Eng. 111, 1450 (2017)

11. R. Cai, M. Zhang, R. Ge, X. Zhang, J. Lyu, Appl. Therm. Eng. (2018) (to be published)

12. MSC.Marc Volume B: Element Library (Santa Ana, CA: MSC Software Corporation, 2010)

13. T. Trzepiecinski, A. Bazan, H.G. Lemu, Int. J. Auto. Tech.-Kor. 16, 849 (2015)

14. T. Trzepiecinski, H.G. Lemu, Stroj. Vestn.-J. Mech. E. 60, 51 (2014) 